\title{
DIABETES MELLITUS ON THE SEVERITY OF COVID-19: META-ANALYSIS
}

\author{
Okky Nurlita Sari \\ Masters Program in Public Health, Universitas Sebelas Maret
}

\begin{abstract}
Background: Considering the prognosis of the COVID-19, approximately $80 \%$ of patients have mild illness, $14 \%$ have severe illness and $5 \%$ critical illness. The initial symptoms do not seem to differ by the presence of comorbidities and the mild clinical presentation of cases was similar in different countries and at different ages. Despite that, studies have shown a worse prognosis for individuals with chronic diseases, such as diabetes mellitus, hypertension, or cardiovascular disease. The aim of this study was to evaluate the impact of diabetes mellitus on the severity of COVID-19 cases.

Subjects and Method: A systematic review and meta-analysis was conducted by PRISMA flow diagram. The articles were collected from Google Scholar, Pubmed, and Science Direct databases, published from 2020 to 2021. Keywords used "diabetes mellitus" AND "severity" AND “COVID-19" OR "SARS-CoV-2" AND “cohort”. Eligibility criteria were defined using the PICO model as follows, (1) population: COVID-19 patients, (2) intervention: diabetes mellitus, (3) comparison: non-diabetes mellitus, and (4) outcome: severity of COVID-19. Articles that met the criteria were analyzed by Revman 5.3.

Results: The current search found a total of 9 studies using 13,143 confirmed COVID19 patients from China, South Korea, and United States, were met the inclusion criteria for the meta-analysis. This study found that diabetes mellitus comorbidity increased severity of COVID-19 patients $(\mathrm{aOR}=1.82 ; 95 \% \mathrm{CI}=1.27$ to $2.61 ; \mathrm{p}<0.001) . \mathrm{I}^{2}=99 \%$ represent high heterogeneity between studies. Therefore, the random effects model was used to combine the studies' results.
\end{abstract}

Conclusion: Diabetes mellitus comorbidity increased severity of COVID-19 patients.

Keywords: covid-19, diabetes melitus, severity

Correspondence:

Okky Nurlita Sari. Masters Program in Public Health, Universitas Sebelas Maret. Jl. Ir. Sutami 36A, Surakarta 57126, Central Java. Email: okkynurlita.s@student.uns.ac.id. Mobile: 082242312116. 